\title{
Literature Review of College Students' Learning Ability
}

\author{
Minna $\mathrm{Wu}^{*}$ \\ The College of Arts and Sciences Yunnan Normal \\ University \\ Kunming, China \\ 823605805@qq.com
}

\author{
Guihong Yang \\ The College of Arts and Sciences Yunnan Normal \\ University \\ Kunming, China
}

\begin{abstract}
This study provides a systematic review of literature on the College Students' Learning Ability (CSLA) from the Student's Platform for Innovation and Entrepreneurship Training Program (SPIETP). There is a need to analyze CSLA intellectually and practically. This review gives the identification of CSLA from the SPIETP, and provides clusters of research literature about CLSA especially in tutorial system, selfregulated learning, project learning and reform of learning. Suggestions for further research are provided.
\end{abstract} Ability

Keywords-college students; the training program; Learning

\section{INTRODUCTION}

In recent years, the Chinese government has launched a range of policies to push forward innovation and entrepreneurship, advocate and boost "Mass Entrepreneurship and Innovation", and has particularly emphasized the cultivation of college students' innovation spirits and innovative entrepreneurial capabilities. However, innovative entrepreneurial capabilities must be based on certain knowledge and skills, while the cultivation and improvement of learning ability can help students with reserves of knowledge and skills. On the basis, students' innovation spirits can be cultivated, students' innovative entrepreneurial capabilities can be improved, the growth and development of students can be boosted, so that students can contribute to the national development.

\section{Definition OF COLlEgE STUDENT's LEARNING ABILITY(CSLA) FROM THE STUDENT'S PLAFORM FOR INNOVATION AND ENTEREPRENEURSHIP TRAINING PROGRAM(SPIETP)}

CSLA from SPIETP refers to: The ability to learn, acquire, internalize and innovate knowledge, to grasp skills, to form learning strategies and to build nice scientific research literacy researchfully, cooperatively, proactively, practically and innovatively, through various measures and methods, driven by tasks, guided by questions and based on professional learning ability in Mass Entrepreneurship and Innovation activities, with college students as the main body.

\section{LITERATURE REVIEW OF CSLA FROM SPIETP}

The research on college student's innovative and entrepreneurial learning ability is conducted extensively, a lot research fruits have come out, and many scholars and experts have put forward their own opinions. Local and foreign scholars have different opinions, but they elaborate college student's innovative and entrepreneurial learning ability mostly at 2 aspects: 1 . Student's benefit; 2 . Teaching and learning.

At the aspect of student's benefit, key words about improvement of student's comprehensive abilities by participating in innovation programs include: interest-driven, question-guided, autonomous study, autonomous practice, autonomous experiment, process-oriented, researchful study and diversified examinations, etc.

$\mathrm{Li}$, Yangfan and Zhu, Xiaodong have put forward that college students should have scientific research training in conjunction with international academic frontiers, social hot spots and undergraduate courses, with focus on the cultivation of professional features, aiming to motivate students' innovative impetus and improve students' innovation quality. Besides, they belive that the trinity innovation ability cultivation model with course teaching as the foundation, with competitive events as carriers and with technical training as the method [1]

Liu, Guangfu has come up with the "1-2-3-4" cultivation model to improve student's innovation ability. "1" refers to 1 main body: Emphasize students' principal status in the course system and lay a foundation for innovation; " 2 " refers to 2 focuses: The focus on autonomous, researchful study and diversified examination methods aiming to cultivate innovation awareness, and the focus on autonomous experiments, internship and graduation design aiming to cultivate innovation spirits; "3" refers to 3 insistences: insistence on autonomous learning for 4 years without interruption, insistence on practice and insistence on scientific research activities for 4 years without interruption, aiming to provide opportunities for innovation practice; " 4 " refers to 4 constructions: Reinforce the construction of teaching teams, the construction of majors and courses, lab construction and stereo textbook construction, aiming to provide quality cultivation resources for innovation [2].

\footnotetext{
*Corresponding author
} 
Zhang, Lei and other people have elaborated the positive effects of Mass Entrepreneurship and Innovation programs on the cultivation of college student's innovative thinking modes and innovation ability, the improvement of student's learning interest and learning efficiency [3] .

As assumed by Wang, Yaming and research partners, the key to success is reasonable selection of subjects, so they have analyzed the influence of teachers' selection of subjects, students' initiative selection of subjects and students' practice and gainings through innovation programs on the cultivation of engineering college students' innovative practice abilities at different stages of programs [4].

By the dimension of teaching, some people suggest that universities and colleges should create learning conditions and improve teaching resources to improve student's innovative and entrepreneurial learning ability, and some people say that teachers should provide rich learning resources, reform appraisal and teaching models. More people pay attention to each aspect of college student's learning ability by the dimension of learning; some of them pay attention to student's autonomous study quality, learning habit, learning motivation, self-monitoring ability, learning status, learning efficiency, learning burnout, study planning, learning performance and learning strategy; some of them pay attention to learning appraisal systems and some research informal learning under the new media environment and the improvement of college student's learning ability in the online course era.

Lei, Xiao has pointed out that learners' autonomy development is influenced by their ideas, so teachers must learn and correct students' autonomous learning opinions first, and consequently advocate students' learning autonomy. As for teaching skills, teachers should build a nice environment for autonomous learning, and pay attention to the cultivation of student's application of learning strategies [5].

Situ, Yingjie has stated that college student's study quality, learning habits, learning methods and self-control ability are all influencing factors of the learning ability. College students should have stricter learning requirements on themselves, universities and college should establish more convenient learning conditions, and teachers should provide richer learning resources [6].

Chen, Hui has raised an opinion that the completion of teaching tasks should be driven by tasks, and has emphasized that tasks should have sense of layers and should be finished in pleasant teaching environments [7] .

Through research, Wang, Xiaobu has found that college students' study planning level is moderate on the whole; study planning has positive correlation with learning performance, students at different study planning levels have obviously different learning performances, the higher study planning level, the better learning performance; all dimension of study planning can forecast learning performance effectively and have positive influence on learning performance [8].

The research results of Zhang, Jungui and other people indicate that science and engineering students have good learning ability and their learning motivation levels are high; at the same time, the factors are helpful for the forming of correct learning attribution patterns.

Lin, Yinling and Ye, Xinzhi have put forward to reform the academic evaluation systems of college students and to encourage college students to turn from surface learning to deep learning.

Xie, Liping has analyzed the present manifestation and reasons of college students' learning burnout, and has put forward the 4 countermeasures to relieve college students' learning burnout, including self-awareness, emotional experience, reaction to setbacks and reflective observation [9].

According to $\mathrm{Li}$, Bin's research results, an important criterion of college student's learning ability is the learning efficiency, while learning team building can improve the learning efficiency of students of local universities and colleges. The "Enjoy Learning, Help Learning, Realize Learning" construction plan is helpful for the improvement of college student's learning efficiency [10].

As presented by Li Chunlan, new students' entrance education should be reinforced to change their learning concepts and improve their awareness, and consequently improve college student's learning ability; the autonomous learning atmosphere should be created, cooperative learning should be conducted, and a special culture environment should be created to realize the education purposes and education effects out of classrooms [11].

The research results of Hsieh and Tzu-Ling prove that students' different personality characteristics and learning motives generate different learning effects, but learning outcomes cannot be forecast accurately when students' backgrounds and learning motives are changed; students' majors are important for learning effects. The research results emphasize the importance of learning motivation and suggest teachers to provide effective learning experience for students, aiming to assure their confidence with their own learning ability [12].

Dahm and other people have described the unique sophomoric practice course of Rowan University: Integrate entrepreneurial strategy cases in the design of a sophomoric multi-disciplinary and multi-level course. Through course training, students are more interested in entrepreneurship and are more willing to select entrepreneurship courses at senior grades. Additionally, more and more universities pay attention to experience in undergraduate education research, but the traditional apprentice mode is infeasible when teachers' ability and provided resources are limited. Under such a condition, the "Embedded Researcher" method can provide research experience for a lot of students in traditional courses and teachers can obtain valuable data at the same time. The author applied this method in a university for Hispanic people, the students were satisfied and meaningful research data was obtained [13].

Thompson and other people have pointed out that introductory science courses have critical roles for undergraduates' selection of the scientific research path. Especially, if freshmen have opportunities to participate in students' scientific practice and incentive program, the 
freshmen may consider joining scientific research careers easily. The researchers developed a introductory science course composed of a range of lab experiments and lectures, which students can participate in and practice [14].

Lee and other people compared 2 universities in SK and USA, and discussed whether higher education could cultivate students' criticalness and creativeness. In the survey results, the author discussed that universities and colleges should provide the education of critical and creative learning according different cultures and awareness [15].

\section{CONCLUSION}

Through literature review, it is found that achievements have been made from research on discussion about college student's innovative and entrepreneurial learning ability at home and abroad. However, almost all the research jobs are done for public universities and colleges, and there is insufficient research on the innovative and entrepreneurial learning ability of students in independent colleges. Under the background, the research on the innovative and entrepreneurial learning ability of students in independent colleges should be reinforced.

\section{REFERENCES}

[1] Li, Yangfan; Zhu, Xiaodong. Scientific Training Plan and Cultivation of College Student's Innovation Ability [J]. China University Teaching, 2011, pp. 74-77.

[2] Liu, Guangfu; Liu, Runhua; Ren, Xuhu. Research on and Practice of "12-3-4" Cultivation Model to Improve Students' Innovation Ability [J]. Vocational \& Technical Education Forum, 2014, pp. 66-70.

[3] Zhang, Lei; Wang, Jing; Xu, Chenshu. Cultivation of Undergraduate Innovation Talents Based on "College Student Innovation and Entrepreneurship Training Program" [J]. Guangdong Chemical Industry. 2016, pp. 222-226.
[4] Wang, Yaming; Tong, Shaocheng; Zhang, Guang'an; Liu, Weidong; Lv, Yi. Exploration and Practice of University-Enterprise Collaborative Education in the Cultivation of Students' Innovation Ability in Application-Oriented Universities [J]. Journal of Liaoning University of Technology, 2016, pp. 87-88.

[5] Lei, Xiao. Cultivation of College Student's Learning Concepts and Learning Autonomy [J]. Foreign Language World, 2005, pp. 68-74.

[6] Situ, Yingjie. Discussion about Cultivation of College Student's Learning Ability [J]. Education Exploration, 2015, pp. 84-87.

[7] Chen, Hui; Li, Chunlan. Survey on and Thinking about Cultivation of College Student's Learning Ability [J].Journal of Suihua University. 2005 .

[8] Wang, Xiaobu. Research on the Sorrelation Between College Student's Study Planning and Learning Performance-Based on the View Angel of Student Engagement [J]. Education Research Monthly, 2016, pp.67-73.

[9] Xie, Liping. Research on Countermeasures to Relieve Learning Burnout of College Students Under the View Angel of Positive Psychology [J].Education and Career, 2015, pp.54-56.

[10] Li, Bin. Empirical Research on Influence of Learning Team on College Student's Learning Efficiency [J].The Party Building and Ideological Education in Schools. 2016,pp.50-52.

[11] Li, Chunlan. Survey on and Thinking about Cultivation of College Student's Learning Ability. Journal of Suihua University. 2005,pp.32134.

[12] Hsieh, Tzu-Ling. Motivation Matters? The Relationship among Different Types of Learning Motivation, Engdgernenl Btjhdviurb and Ledming OuLcumei) uf UndergraduiiU; SludtmU iri Taiwan[J]. Higher EdutdLiun: The International Journal of Higher Education and Educational Planning. 2014, pp.417-433.

[13] Dahm, Kevin; Riddell, William; Merrill, Thomas; Harvey, Roberta; Weiss, Leigh. Implementing Entrepreneurial Assignments in a Multidisciplinary, Sophomore-Level Design Course [J]. Advances in Engineering Education. 2013 pp.36.

[14] Thompson. Meredith M.; Pastorino, Lucia; Lee. Star; Lipton. Paul. Research and Teaching: Rccnvisioning the Introductory Science Course as a Cognitive Apprenticeship [J]. Journal of College Science Teaching.2016,pp.8-9

[15] Lee, Hye-Jung; Lee. Jihyun; Makara. Kara A.; Fishman. Barr> J.; Hong, Young-11.Does Higher Education Foster Critical and Creative Learners? An Exploration of Two Universities in South Korea and the USA [J]. Higher Education Research and Development. 2015,pp.131-146. 